\title{
Kikuchi-Fujimoto disease associated with primary Sjögren's syndrome - literature review based on a case report
}

\author{
Katarzyna Wiśniewska ${ }^{1}$, Katarzyna Pawlak-Buś², Piotr Leszczyński \\ ${ }^{1}$ Department of Rheumatology and Osteoporosis, J. Struś Memorial Multidisciplinary Municipal Hospital in Poznań, Poland \\ ${ }^{2}$ Department of Rheumatology and Rehabilitation, Poznań University of Medical Sciences, Poland
}

\begin{abstract}
Primary Sjögren's syndrome (pSS) is a chronic, autoimmune disease predominantly involving exocrine glands. Lymphadenopathy is one of the possible symptoms of pSS. It may also suggest development of non-Hodgkin lymphoma (NHL), the most severe complication of pSS, or be a symptom of less common diseases, such as Kikuchi-Fujimoto disease (KFD), presented in this paper. Kikuchi-Fujimoto disease is an extremely rare, benign and self-limiting disorder, characterized by regional lymphadenopathy.

This paper presents a case of previously unreported association of pSS, KFD and renal cancer in a patient with recurrent cervical lymphadenopathy, as well as a discussion on the coexistence of these diseases based on available literature searching for PubMed, Scopus and Google Scholar databases, particularly in this subject. These three clinical entities may manifest lymphadenopathy each, causing a diagnostic dilemma. The treatment is also challenging under such circumstances. In this particular situation, it was a combination of immunosuppressive therapy and surgery.
\end{abstract}

Key words: renal cancer, lymphadenopathy, primary Sjögren's syndrome, Kikuchi-Fujimoto disease.

\section{Introduction}

Primary Sjögren's syndrome (pSS) is a chronic, autoimmune disease that mainly affects exocrine glands. The clinical picture comprises sicca syndrome, constitutional symptoms (fever, fatigue, chronic pain often associated with polyarthralgia and myalgia) and organ-specific involvement $[1,2]$. The EULAR Sjögren's Syndrome Disease Activity Index (ESSDAI) is a clinical index designed to measure disease activity in patients with pSS recommended by the European League Against Rheumatism (EULAR) [3].

At the moment a variety of drugs are used to treat pSS according to EULAR recommendations for the management of this disease. The treatment depends on an organ involvement based approach, for which topical treatment (eye drops; moistures) and systemic therapy including non-steroidal anti-inflammatory drugs (NSAIDs), glucocorticoids (GCS), disease-modifying antirheumatic drugs (DMARDs) and biologics are applied [1, 4, 5].
The attitude to developing new therapies for pSS has changed in the last several years with the recognition that extraglandular manifestation may lead to serious complications [5].

It also seems to be relevant that pSS is a well-established risk factor for $\mathrm{NHL}$, one of the main causes of decreased survival that occurs in around $5-10 \%$ of patients. Primary Sjögren's syndrome has the highest prevalence of lymphoma among all autoimmune diseases [6-8].

On the other hand, benign processes can also develop in pSS patient's lymph nodes and salivary glands, like reactive lymphoid proliferation, including lymphoepithelial sialadenitis (LESA) also known as myoepithelial sialadenitis (MESA). Lymphoepithelial/myoepithelial sialadenitis displays a variable aggressiveness even without malignant features [7]. An example of aggressiveness without malignancy is presented below: Kikuchi-Fujimoto disease (KFD), a benign and self-limiting disorder, characterized by regional cervical lymphadenopathy [9]. 
The diagnosis of KFD is largely based on histopathological evaluation [10]. This is a reason why lymphadenopathy, a possible symptom of pSS, needs careful diagnostic follow-up. The correlation of pSS and KFD has been previously noted worldwide and may impact further diagnostic procedures and treatment [11-18].

\section{Objective and methods}

The aim of this article was to present the clinical problem of pSS, KFD, and renal cancer coexistence, regarding lymphadenopathy as a possible clinical manifestation of these diseases separately. The authors searched PubMed, Scopus and Google Scholar databases' sources using the following combination of words: Kikuchi-Fujimoto disease, primary Sjögren's syndrome, renal cancer, lymphadenopathy. The language was restricted to English. The discussion was based on the case study and a literature review.

\section{Results}

\section{Case report}

The 38-year-old Caucasian woman was suffering from recurrent fever $\left(38^{\circ} \mathrm{C}\right)$ arthralgia and cervical, bilateral, painful lymphadenopathy. After exclusion of infection (including HBV, HCV, HIV, EBV, CMV and Borrelia), lymph node biopsy was performed and the histopathological examination revealed histiocytic necrotizing lymphadenitis - Kikuchi-Fujimoto disease.

The patient had a past medical history of hypothyroidism and reported no family history of malignancies, autoimmune diseases, or increased incidents of infections. Initially, symptomatic treatment with NSAIDs was successful.

The next year, in 2017, diagnosis of pSS was established due to xerophthalmia and xerostomia with positive ANA (1 : 320), anti-SSA/Ro antibodies, abnormally low level of tear production in Schirmer's test result $(4 \mathrm{~mm} / 5$ minutes in the right eye and $3 \mathrm{~mm} / 5$ minutes in the left eye) and decreased saliva secretion in the unstimulated salivary test $(<0.1 \mathrm{ml} /$ minute). The final diagnosis was supported by the American College of Rheumatology/European League Against Rheumatism (ACR/EULAR) 2016 classification criteria [19].

Due to recurrent fever and painful lymphadenopathy the patient was referred to the hospital. On admission, she was in overall fairly good condition. Physical examination revealed tender, non-mobile, multiple bilateral, cervical lymphadenopathy with no other inconsistencies.

Apart from positive antinuclear antibodies, there were also slight disturbances in laboratory results in Table I and electrophoresis in Table II.
Table I. Laboratory blood results

\begin{tabular}{|c|c|c|c|}
\hline $\begin{array}{l}\text { Laboratory test } \\
\text { (normal values) }\end{array}$ & $\begin{array}{l}\text { Patient } \\
\text { results }\end{array}$ & $\begin{array}{l}\text { Laboratory test } \\
\text { (normal values) }\end{array}$ & $\begin{array}{l}\text { Patient } \\
\text { results }\end{array}$ \\
\hline $\begin{array}{l}\text { Hemoglobin } \\
(7.4-9.9 \mathrm{mmol} / \mathrm{l})\end{array}$ & 6.9 & $\begin{array}{c}\text { ESR } \\
(3-15 \mathrm{~mm} / \mathrm{h})\end{array}$ & 23 \\
\hline $\begin{array}{l}\text { Hematocrit } \\
(0.34-0.45 \mathrm{I} / \mathrm{l})\end{array}$ & 0.32 & $\begin{array}{c}\text { CRP } \\
(0.0-5.0 \mathrm{mg} / \mathrm{l})\end{array}$ & 32.4 \\
\hline $\begin{array}{l}\text { Erythrocytes } \\
\left(4.0-5.5 \times 10^{12} / l\right)\end{array}$ & 3.92 & $\begin{array}{c}\text { Creatinine } \\
(44-106 \mu \mathrm{mol} / \mathrm{l})\end{array}$ & 70 \\
\hline $\begin{array}{l}\text { Leukocytes } \\
\left(4.0-11.0 \times 10^{12} / 1\right)\end{array}$ & 6.1 & $\begin{array}{c}\text { ALT } \\
(4-45 \cup / l)\end{array}$ & 38 \\
\hline $\begin{array}{l}\text { Neutrophils } \\
\left(1.5-7.7 \times 10^{12} / l\right)\end{array}$ & 4.9 & $\begin{array}{c}\text { TSH } \\
(0.55-4.78 \mu \mathrm{l} \mathrm{U} / \mathrm{ml})\end{array}$ & 0.54 \\
\hline $\begin{array}{l}\text { Eosinophils } \\
\left(0.0-0.5 \times 10^{12} / l\right)\end{array}$ & 0.0 & $\begin{array}{c}\text { CK } \\
(26-192 \mathrm{U} / \mathrm{l})\end{array}$ & 80 \\
\hline $\begin{array}{l}\text { Basophils } \\
\left(0.0-0.2 \times 10^{12} / 1\right)\end{array}$ & 0.0 & $\begin{array}{c}C 4 \\
(0.1-0.4 \mathrm{~g} / \mathrm{l})\end{array}$ & $<0.02$ \\
\hline $\begin{array}{l}\text { Monocytes } \\
\left(0.1-1.8 \times 10^{12} / 1\right)\end{array}$ & 0.4 & $\begin{array}{c}C 3 \\
(0.9-1.8 \mathrm{~g} / \mathrm{l})\end{array}$ & 0.83 \\
\hline $\begin{array}{l}\text { Lymphocytes } \\
\left(1.0-4.8 \times 10^{12} / l\right)\end{array}$ & 0.66 & $\begin{array}{c}\text { LDH } \\
(135-214 \mathrm{U} / \mathrm{l})\end{array}$ & 178 \\
\hline $\begin{array}{l}\text { Platelets } \\
\left(130-440 \times 10^{12 / l)}\right.\end{array}$ & 203 & $\begin{array}{c}\mathrm{RF} \\
(0.0-14.0 \mathrm{lU} / \mathrm{ml})\end{array}$ & 16.0 \\
\hline
\end{tabular}

ALT - alanine aminotransferase, C3 - complement component C3, $C 4$ - complement component $C 4, C K$ - creatine kinase, $C R P-C$-reactive protein, ESR - erythrocyte sedimentation rate, $L D H$ - lactate dehydrogenase, $M C V$ - mean corpuscular volume, RF-rheumatoid factor, TSH - thyroid stimulating hormone.

Table II. Electrophoresis results

\begin{tabular}{|lc|}
\hline $\begin{array}{l}\text { Laboratory test } \\
\text { (normal values) }\end{array}$ & Patient results \\
\hline $\begin{array}{l}\text { Total protein } \\
(60-80 \text { g/l) }\end{array}$ & 58 \\
\hline $\begin{array}{l}\text { Albumin } \\
(53.1-65.5 \%)\end{array}$ & 57.09 \\
\hline $\begin{array}{l}\text { Globulin } \alpha-1 \\
(2.3-4.6 \%)\end{array}$ & 5.2 \\
\hline $\begin{array}{l}\text { Globulin } \alpha-2 \\
(6.7-12.9 \%)\end{array}$ & 12.12 \\
\hline $\begin{array}{l}\text { Globulin } \beta-1 \\
(5.9-10.7 \%)\end{array}$ & 9.97 \\
\hline $\begin{array}{l}\text { Globulin } \beta-2 \\
(3.7-6.0 \%)\end{array}$ & 3.8 \\
\hline $\begin{array}{l}\text { Globulin } \gamma \\
(11.6-19 \%)\end{array}$ \\
\hline
\end{tabular}

Lymphadenopathy in the context of autoimmunological diseases may also be a symptom of common variable immunodeficiency (CVID) [20]. Due to the lack of history of recurrent infections and normal ranges of IgG, IgA, IgM serum levels, CVID was not followed up further in the present case. 
Table III. Summary of Kikuchi-Fujimoto disease association with primary Sjögren's syndrome cases

\begin{tabular}{|lcccccc|}
\hline $\begin{array}{l}\text { Author } \\
\text { (year) }\end{array}$ & Race/origin & Gender & $\begin{array}{c}\text { Age of KFD } \\
\text { diagnosis }\end{array}$ & $\begin{array}{c}\text { KFD diagnosis prior } \\
\text { to pSS's onset }\end{array}$ & Recurrence & Treatment \\
\hline $\begin{array}{l}\text { Miyashita et al. } \\
\text { (2003) }\end{array}$ & Japanese & Female & 42 & No & Yes & GCs \\
\hline $\begin{array}{l}\text { Soy et al. } \\
\text { (2007) }\end{array}$ & NR & Female & 24 & Simultaneously & NR & GCs, HCQ \\
\hline $\begin{array}{l}\text { Ogata et al. } \\
\text { (2010) }\end{array}$ & NR & Male & 7 & Yes & Yes & GCs mizoribine \\
\hline $\begin{array}{l}\text { Sopeña et al. } \\
\text { (2012) }\end{array}$ & NR & Female & 27 & Yes & NR & NR \\
\hline $\begin{array}{l}\text { Bogusz et al. } \\
\text { (2013) }\end{array}$ & African & Female & 42 & Yes & Yes & No \\
\hline $\begin{array}{l}\text { Radfar et al. } \\
(2013)\end{array}$ & Indian & Female & 32 & Yes & Yes & HCQ \\
\hline $\begin{array}{l}\text { Zhang et al. } \\
\text { (2015) }\end{array}$ & Chinese & Female & 17 & Yes & Yes & GCs \\
\hline $\begin{array}{l}\text { Al-Allaf et al. } \\
(2018)\end{array}$ & NR & Female & 33 & Simultaneously & NR & NR \\
\hline $\begin{array}{l}\text { Presented case } \\
(2020)\end{array}$ & Polish & Female & 38 & Yes & Yes & GCs HCQ \\
\hline
\end{tabular}

GCS - glucocorticoids, HCQ - hydroxychloroquine, MTX-methotrexate, NR - not reported.

The diagnostic process including abdomen cavity imaging studies (USG, CT, MR) revealed the presence of a tumor mass in the right kidney of unknown nature. There were no morphological changes of lungs in high-resolution computed tomography (HRCT). Also diffusion lung capacity for carbon monoxide (DLCO) results did not reveal any abnormalities. No other organ involvement specific for pSS was noted. Sjögren's Syndrome Disease Activity Index scored 17.

The patient was still suffering from fever and painful lymphadenopathy causing dyspnea. Due to inefficacy of treatment with NSAIDs, hydroxychloroquine (HCQ) and oral GCS, the decision of therapy intensification was taken. We administered 3 g methylprednisolone intravenously (1000 mg for three consecutive days) and initiated $15 \mathrm{mg}$ methotrexate (MTX) subcutaneously per week. The steroid infusion, in a dose of $1.5 \mathrm{~g}$, was repeated twice the subsequent month, then it was switched to oral therapy, tapering with the dose.

Following therapy, symptoms withdrawal allowed the patient to be referred for surgery. Partial nephrectomy was performed and the clear cell carcinoma of kidney diagnosis was established due to histopathological examination (G2, T1b, NO, MO).

Treatment with MTX and HCQ was sustained. The methotrexate final dosage was $25 \mathrm{mg}$ per week subcutaneously. The patient responded and tolerated the therapy well with full remission of symptoms within 3 months. At a one-year follow-up, the patient sustained steroid-free remission. As far as oncological follow-up was concerned, no renal carcinoma relapse was observed. MTX and HCQ therapy is being continued.

In total, eight articles were identified by the search criteria and 10 patients (including ours) were analyzed (Table III) [11-18].

In the present group there were 9 females and 1 male with the age range from 7 to 42 years. Kikuchi-Fujimoto disease was diagnosed simultaneously in 2 patients, prior to onset of pSS in 7 patients and after onset of pSS in 1 patient.

\section{Discussion}

Kikuchi-Fujimoto disease or histiocytic necrotizing lymphadenitis is a benign and self-limiting disorder, characterized by regional lymphadenopathy, most commonly in cervical regions, frequently with concomitant involvement of axillary and/or supraclavicular lymph nodes, with tenderness, usually accompanied by mild fever.

Less frequent symptoms include night sweats, weight loss, vomiting, nausea, upper respiratory symptoms, headache, or arthralgia. The onset is acute or subacute, evolving for several weeks. It is distributed with higher prevalence among Japanese and other Asian individuals than in Caucasians. It occurs most commonly in young women, < 40 years of age [9, 21-24]. Kikuchi-Fujimoto disease was originally reported in 1972 in Japan [25, 26].

Diagnosis is based on histopathological analysis with characteristic single or multiple areas within the 
lymph node containing necrosis and histiocytic cellular infiltrate. The capsule of the node may be invaded and perinodal inflammation is common $[9,10,21]$.

The differential diagnosis of KFD should exclude the following entities: malignancies, particularly non-Hodgkin lymphomas, autoimmune disorders and infectious causes. Among infections, the most common bacterial (Staphylococcus aureus and group A $\beta$-hemolytic Streptococcus) cause of suppurative lymphadenitis should be taken into consideration as well as less common ones such as Bartonella henselae (cat scratch disease) or Mycobacterium.

Lymphadenopathy is also commonly caused by viruses (including, among others, EBV, CMV, HIV, rubella, rhinovirus and adenovirus), toxoplasmosis and various fungal infections [9, 10, 21-24].

This disorder is enigmatic and no other specific diagnostic laboratory tests are available to confirm it. Most commonly the patient's laboratory findings are in normal ranges. In some cases there is mild anemia, leukopenia (20-58\% of cases) or leukocytosis ( $2-5 \%$ of cases), elevated erythrocyte sedimentation rate, increased lactate dehydrogenase $(\mathrm{LDH})$, increased $\mathrm{C}$-reactive protein and elevated transaminases [9, 21-23]. Its recognition is crucial because it can be mistaken for malignancies, especially lymphomas, which is even more important in pSS patients, who are more susceptible to lymphoma evaluation $[7,27]$.

The exact pathophysiology of KFD is unknown, but there are two possible theories. It has been hypothesized that KFD may result as a reaction to a viral infection. Infection of parvovirus B19, Epstein-Barr virus (EBV), herpes virus 6, herpes virus 8, cytomegalovirus (CMV), varicella zoster virus, were taken into consideration as a possible trigger of KFD evaluation, but a series of studies did not confirm it $[9,21,28]$. There are also some reports that it may be associated with autoimmune diseases, especially systemic lupus erythematosus (SLE).

Kucukardali et al. [22] evaluated 244 cases of KFD worldwide, finding that $32(13 \%)$ of those tested were also diagnosed with SLE Some authors have even suggested that KFD may herald SLE and recommend following KFD patients with cutaneous lesions and considering an autoimmune workup or rheumatological referral $[21,22]$.

According to another study, there have been three patterns of presentation of Kikuchi-Fujimoto disease and systemic lupus erythematosus coexistence. In the review, KFD occurred prior to the onset of SLE in $30 \%$ of patients, simultaneously with SLE in $47 \%$ of patients and after SLE in 23\% of patients [29].

Apart from systemic lupus erythematosus, Kikuchi-Fujimoto disease was also reported with mixed connective tissue disease, anti-phospholipid syndrome, thyroiditis, polymyositis, scleroderma, autoimmune hepatitis and adult-onset Still's disease [9, 21, 22, 30]. Only a few studies have also suggested that KFD may be associated with pSS [11-18].

As mentioned earlier, KFD is classically believed to be a benign, self-limited condition. Spontaneous, complete resolution of symptoms usually occurs within the period of 1 to 4 months. An estimated 3\% to $4 \%$ of patients may experience recurrent episodes. Patients usually do not require treatment, except those with persistent fever or lymph node tenderness [24]. For symptomatic control NSAIDs are recommended. In most severe cases, when symptoms are not adequately controlled, GCs alone or in combination with HCQ may be a treatment of choice, but there is no consensus of dosage and duration of such therapy [21, 31, 32].

Kikuchi-Fujimoto disease can be confused with malignancy but is rarely associated with solid tumors. The case reports available in the literature present examples of KFD comorbidity with breast, [27] tongue, [33], stomach, [34] thyroid, [35] but no renal carcinoma.

The diagnosis of KFD before the pSS onset and the lymphadenopathy recurrence was also a characteristic feature of the present case. The symptoms resolved temporarily after treatment with NSAIDs, but in a few months high fever and painful lymphadenopathy relapsed. The diagnostic process revealed the coexistence of pSS. Consistent symptoms were arguments for intensification of the treatment. Apart from steroids with tapering doses, successful therapy with HCQ and MTX was instituted.

Through a systematic search, we reviewed 8 articles and analyzed 10 patients with KFD and pSS (including our patient) coexistence. All the KFD diagnoses were supported by the histopathological evaluation. There were two patients diagnosed with KFD and pSS simultaneously.

Soy et al. [13] reported a female with severe symptoms, who was administered high doses of methylprednisolone, tapering in dose and HCQ and remained asymptomatic in 10 months' follow-up.

Al-Allaf et al. [17]. reported a female with mild symptoms, but no details regarding treatment were mentioned Seven patients were diagnosed with KFD before the onset of pSS (including the one presented in this paper).

Ogata et al. [15] reported a male, diagnosed with KFD and treated with prednisone for three months. One and a half years later, due to a relapse of symptoms, pSS diagnosis was established. Treatment with prednisolone and mizoribine was instituted, leading to symptoms resolution. 
Sopeña et al. [16], presented a series including two women, diagnosed with pSS, two, and ten years, respectively, after the diagnosis of KFD. One of them suffered three relapses of cervical lymphadenopathy over a period of three years.

Zhang et al. [11] presented a female first diagnosed with KFD and treated with methylprednisolone successfully. Four years later symptoms relapsed and pSS diagnosis was established. The patient recovered spontaneously.

Bogusz et al. [12] reported female with KFD followed by pSS 19 months later and recurrence of KFD after almost 8 years. The last case presented a female diagnosed with KFD followed with pSS in a few years. Monotherapy of HCQ was instituted and remission of symptoms achieved. [18]

One patient was diagnosed with pSS before KFD onset. Miyashita et al. [14] reported a female who was diagnosed with pSS when she was 16 years old. The disease was controlled mostly by $5 \mathrm{mg} /$ day of prednisone. Kikuchi-Fujimoto disease diagnosis was instituted 26 years later. Symptoms and laboratory abnormalities withdrew within three weeks after treatment with $20 \mathrm{mg} /$ day of prednisolone [14].

Accordingly, pSS can occur simultaneously, prior to and after the onset of Kikuchi-Fujimoto disease. In the largest number of presented cases, it occurred after the KFD onset.

Although Kikuchi-Fujimoto disease appears to be a distinct clinical and pathological entity, it may not be the same disease in the context in which it occurs. Taking into consideration patients who were first diagnosed with KFD, there has been a higher recurrence rate than reported in the literature (3-4\%). The literature search also revealed that patients with recurrences of KFD were more susceptible to autoimmune disease development [16, 24].

As mentioned before, KFD is a benign and self-limiting disorder usually not requiring treatment. In six of the presented cases, patients suffered from severe symptoms and required treatment intensification. Patients were administered GCs alone [11, 14], in combination with HCQ [13], or mizoribine [15]. Monotherapy with HCQ was successful in one case [18]. We reported a patient treated with GCS, HCQ and MTX with full remission of symptoms within 3 months.

\section{Conclusions}

The authors present a rare case of pSS, KFD and renal carcinoma coexistence in a patient with cervical lymphadenopathy as a key symptom. Each of these entities may manifest with lymph node enlargement separately.

The findings of the literature review suggest that pSS and other autoimmune diseases are likely to be as- sociated with KFD. No coincidence of renal carcinoma with KFD was observed. The KFD's recurrence may be linked to the risk of autoimmune diseases, including pSS's development.

Such clinical manifestation should be followed up by appropriate clinical and laboratory workup to exclude underlying pSS conditions for KFD patients. A histopathological examination must be a part of the diagnostic process to distinguish malignancy, especially lymphoma, as recommendations regarding the treatment of these entities are vastly different.

The authors declare no conflict of interest.

\section{References}

1. Ramos-Casals M, Brito-Zerón P, Sisó-Almirall A, Bosch X. Primary Sjögren syndrome. BMJ 2012; 344: e3821, DOI: 10.1136/ bmj.e3821.

2. Psianou K, Panagoulias I, Papanastasiou AD, et al. Clinical and immunological parameters of Sjögren's syndrome. Autoimmun Rev 2018; 17: 1053-1064, DOI: 10.1016/j.autrev.2018.05.005.

3. Seror R, Ravaud P, Bowman SJ, et al. EULAR Sjögren's syndrome disease activity index: development of a consensus systemic disease activity index for primary Sjögren's syndrome. Ann Rheum Dis 2010; 69: 1103-1109, DOI: 10.1136/ard.2009.110619.

4. Both T, Dalm VA, van Hagen PM, van Daele PL. Reviewing primary Sjögren's syndrome: beyond the dryness - From pathophysiology to diagnosis and treatment. Int J Med Sci 2017; 14 : 191-200, DOI: 10.7150/ijms.17718.

5. Ramos-Casals M, Brito-Zerón P, Bombardieri S, et al. EULAR recommendations for the management of Sjögren's syndrome with topical and systemic therapies. Ann Rheum Dis 2020; 79: 3-18, DOI: 10.1136/annrheumdis-2019-216114.

6. Kleinstern G, Maurer MJ, Liebow M, et al. History of autoimmune conditions and lymphoma prognosis. Blood Cancer J 2018; 8: 73, DOI: 10.1038/s41408-018-0105-4.

7. Alunno A, Leone MC, Giacomelli R,et al. Lymphoma and lymphomagenesis in primary Sjögren's syndrome. Front Med (Lausanne) 2018; 5: 102, DOI: 10.3389/fmed.2018.00102.

8. Sandhya P, Kurien BT, Danda D, Scofield RH. Update on pathogenesis of Sjögren syndrome. Curr Rheumatol Rev 2017; 13: 5-22, DOI: 10.2174/1573397112666160714164149.

9. Deaver D, Naghashpour M, Sokol L. Kikuchi-Fujimoto disease in the United States: three case reports and review of the literature [corrected]. Mediterr J Hematol Infect Dis 2014; 6: e2014001, DOI: 10.4084/MJHID.2014.001.

10. Hutchinson CB, Wang E. Kikuchi-Fujimoto disease. Arch Pathol Lab Med 2010; 134: 289-293, DOI: 10.1043/1543-2165134.2.289.

11. Zhang J, Yang J, Weng WW, et al. Kikuchi-Fujimoto disease associated with Sjögren's syndrome: a case report and review of the literature. Int J Clin Exp Med 2015; 8: 17061-17066.

12. Bogusz AM, Bhargava P. Recurrent histiocytic necrotizing lymphadenitis with a long latency in a patient with autoimmunity: a case report and review of literature. Int J Surg Pathol 2012; 21: 287-296, DOI: 10.1177/1066896912467369. 
13. Soy M, Peynirci H, Bilgi S, et al. Kikuchi-Fujimoto disease coexisted with Sjögren's syndrome. Clin Rheumatol 2007; 26 607-608, DOI: 10.1007/s10067-005-0184-z.

14. Miyashita Y, Yamaguchi M, Fujimoto W. Painful indurated erythema suggestive of Kikuchi-Fujimoto disease in a patient with primary Sjögren's syndrome. J Dermatol 2003; 30: 608611, DOI: 10.1111/j.1346-8138.2003.tb00443.x.

15. Ogata S, Bando Y, Saito N, et al. Kikuchi-Fujimoto disease developed into autoimmune disease: a report of two cases. Mod Rheumatol 2010; 20: 301-305, DOI: 10.1007/s10165-0090269-7.

16. Sopeña B, Rivera A, Vázquez-Triñanes C, et al. Autoimmune manifestations of Kikuchi disease. Semin Arthritis Rheum 2012; 41: 900-906, DOI: 10.1016/j.semarthrit.2011.11.001.

17. Al-Allaf AW, Yahia YM. Kikuchi-Fujimoto disease associated with Sjögren's syndrome: A Case Report. Eur J Case Rep Intern Med 2018; 5: 000856, DOI: 10.12890/2018_000856.

18. Radfar A, Radfar M, Moser K, Scofield R. Kikuchi-Fujimoto disease in patients with Sjögren's Syndrome. Open J Pathol 2013; 5: 32-36, DOI: 10.4236/ojpathology.2013.31006.

19. Shiboski CH, Shiboski SC, Seror R, et al. 2016 American College of Rheumatology/European League Against Rheumatism classification criteria for primary Sjögren's syndrome: a consensus and data-driven methodology involving three international patient cohorts. Arthritis Rheumatol 2017; 69: 35-45, DOI: 10.1002/art.39859.

20. Cunningham-Rundles $C$. The many faces of common variable immunodeficiency. Hematology Am Soc Hematol Educ Program 2012; 2012: 301-305, DOI: 10.1182/asheducation-2012.1.301.

21. Dumas G, Prendki V, Haroche J, et al. Kikuchi-Fujimoto disease: retrospective study of 91 cases and review of the literature. Medicine (Baltimore) 2014; 93: 372-382, DOI: 10.1097/ MD.0000000000000220.

22. Kucukardali Y, Solmazgul E, Kunter E, et al. Kikuchi-Fujimoto disease: analysis of 244 cases. Clin Rheumatol 2007; 26: 5054, DOI: 10.1007/s10067-006-0230-5.

23. Perry AM, Choi SM. Kikuchi-Fujimoto Disease: a review. Arch Pathol Lab Med 2018; 142: 1341-1346, DOI: 10.5858/arpa. 2018-0219-RA.

24. Singh JM, Shermetaro CB. Kikuchi-Fujimoto disease in Michigan: a rare case report and review of the literature. Clin Med Insights Ear Nose Throat 2019; 12: 1179550619828680, DOI: $10.1177 / 1179550619828680$
25. Kikuchi M. Lymphadenitis showing focal reticulum cell hyperplasia with nuclear debris and phagocytosis. A clinicopathological study. Acta Hematol Jpn 1972; 35: 379-380.

26. Fujimoto Y, Kozima T, Yamaguchi K. Cervical subacute necrotizing lymphadenitis: a new clinicopathological entity. Naika 1972; 20: 920-927.

27. Hwang JP. Kikuchi disease mimicking metastatic lymphadenopathy on 18F-FDG PET/CT in patients with breast cancer. Nucl Med Mol Imaging 2015; 49: 167-168, DOI:10.1007/ s13139-015-0318-4.

28. Rosado FG, Tang YW, Hasserjian RP, et al. Kikuchi-Fujimoto lymphadenitis: role of parvovirus B-19, Epstein-Barr virus, human herpesvirus 6, and human herpesvirus 8 . Hum Pathol 2013; 44: 255-259, DOI: 10.1016/j.humpath.2012.05.016.

29. Baenas DF, Diehl FA, Haye Salinas MJ, et al. Kikuchi-Fujimoto disease and systemic lupus erythematosus. Int Med Case Rep J 2016; 9: 163-167, DOI: 10.2147/IMCRJ.S106396.

30. Sharma V, Rankin R. Fatal Kikuchi-like lymphadenitis associated with connective tissue disease: a report of two cases and review of the literature. Springerplus 2015; 4: 167, DOI: 10.1186/s40064-015-0925-7.

31. Jang YJ, Park KH, Seok HJ. Management of Kikuchi's disease using glucocorticoid. J Laryngol Otol 2000; 114: 709-711, DOI: 10.1258/0022215001906561.

32. Rezai K, Kuchipudi S, Chundi V, et al. Kikuchi-Fujimoto disease: hydroxychloroquine as a treatment. Clin Infect Dis 2004; 39: e124-e126, DOI: 10.1086/426144.

33. Maruyama T, Nishihara K, Saio $M$, et al. Kikuchi-Fujimoto disease in the regional lymph nodes with node metastasis in a patient with tongue cancer: A case report and literature review. Oncol Lett 2017; 14: 257-263, DOI: 10.3892/ ol.2017.6139.

34. Radhi JM, Skinnider L, McFadden A. Kikuchi's lymphadenitis and carcinoma of the stomach. J Clin Pathol 1997; 50: 530531, DOI: 10.1136/jcp.50.6.530.

35. Garg S, Villa M, Asirvatham JR, et al. Kikuchi-Fujimoto disease masquerading as metastatic papillary carcinoma of the thyroid. Int J Angiol 2015; 24: 145-150, DOI: 10.1055/s-00331358784 . 